\title{
Casita de niños
} Una experiencia autoeducativa comunitaria

Sor Inés Larrahondo La Balsa - Municipio de Buenos Aires Santander de Quilichao, Cauca

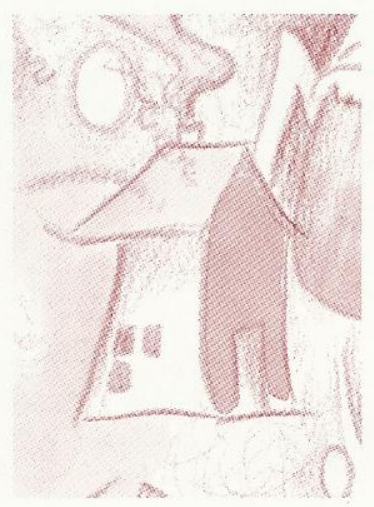

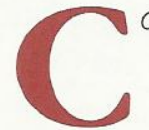

asita de niños es una propuesta educativa a nivel preescolar. Surgió en 1979 en la comunidad de Villa Rica, y se extendió posteriormente a las comunidades de San Nicolás, La Balsa y Quinamayó, coordinadas por organizaciones comunitarias como:Asociación de amigos de la Casita de los Niños en Villa Rica, Asociación Senderos del Mañana en San Nicolás, Grupo de Integración Rural en La Balsa y ADECAR en Quinamayó ubicadas en el Norte del Cauca y Sur delValle para consolidar una alternativa que brinde a las nuevas generaciones una mayor afirmación de la identidad del pueblo negro.

Desde su fundación, esta zona ha sido habitada por comunidades negras descendientes de antiguos esclavos africanos que, convertidos en campesinos, mantuvieron características culturales de nuestros ancestros. El despojo de tierras, el tipo de educación que se ha impartido y la desarticulación familiar a causa de las constantes emigraciones, han contribuido al debilitamiento de la identidad.

En este proceso los más afectados son los niños debido a que sus madres han tenido que ir a trabajar y ellos han quedado al cuidado de sus abuelos o hermanos un poco mayores que ellos, expuestos a diversos accidentes; pese a que en Colombia se ha creado el ICBF, los niños de Villa Rica, San Nicolás, La Balsa y Quinamayó entre otras, no se benefician de este servicio. Esta situación generó un 
proceso de reflexión al interior de las comunidades que han decidido organizarse alrededor de la problemática y crear las Casitas de niños.

La Empresa de Cooperación al Desarrollo EMCODES retoma nuestra iniciativa, y conjuntamente empezamos a darle forma al programa para la atención de los niños menores de seis años, y en 1989 surge la idea de crear la Asociación casita de niños con el propósito de generar un espacio de reflexión, planeación y evaluación del trabajo, como una estrategia para la gestión y ejecución de proyectos. Hay Casitas que logran apoyos a nivel individual como el apoyo que da CCF a las Casitas de San Nicolás y La Balsa a través del grupo de Integración Rural, Condoroa del Mañana y el apoyo del Plan Internacional de Padrinos en Quinamayó, Valle.

A nivel de la Asociación en general destacó el apoyo económico de la Swissaid,y de manera muy especial el de la comunidad, sin desconocer otros dados por ONGs y entidades gubernamentales (en muy poca escala este último).

\section{Aspecto Organizativo y Administrativo de la Asociación}

La Asociación cuenta con una estructura administrativa y organizativa determinada teniendo en cuenta los principios de la democracia. Su funcionamiento parte de los grupos de apoyo de las Casitas de niños que son las células básicas de la organización.

La Asociación se estructura en: Grupos de apoyo, Comité regional, Comité coordinador y la Asamblea general.

\section{Caracterización de la experiencia}

El trabajo se desarrolla bajo dos modalidades; educación formal con niños menores de seis años y educación no formal que se desarrolla con los padres, exalumnos, jóvenes y maestros.

Se parte de las premisas:

* La comunidad en general y la familia en particular como principales agentes educativos deben estar
17 C inolucradosenelproceso formainvolucrados en el proceso formativo que se desarrolla con los niños.

* Las Casitas de los niños deben ser administradas por la comunidad mediante grupos de base organizados. Se considera que si la comunidad asume el proceso, la experiencia perdurará en el tiempo y se obtendrán mayores y mejores resultados. * El trabajo de las Casitas de niños involucra a la familia y a la comunidad, en donde, además de realizar actividades educativas con los niños, se realizan acciones dirigidas a la formación de la familia y a la comunidad en general, que contribuyan a la organización y desarrollo comunitario.

* Se pretende fortalecer la identidad etnocultural de los niños a través del conocimiento de la historia, permitiéndole y/o ayudándole a reconocer estos valores de su comunidad y de las otras.

Se reconoce al niño como un ser importante, que merece nuestro amor, atención y cuidado, pues en la niñez es cuando se estructura la personalidad del individuo, asimilando valores y antivalores que propician la construcción de la identidad y la autoestima, o por el contrario, debilitarla. Por lo tanto, la metodología de trabajo y sus contenidos están encaminados a desarrollar las múltiples dimensiones del niño, como la creatividad, la investigación, la criticidad, la valoración de él mismo, de otros, de la naturaleza, de sus costumbres y la proyección de sus aspiraciones hacia el entorno social.

\section{Casita de niños: experiencia etnoeducativa}

\section{Nuestra Historia}

Nuestra historia es uno de los proyectos que se desarrolla con los niños, a través de un proyecto de aula que involucra aspectos como: partir del conocimiento e inquietudes de 
los niños acerca del tema, hacer recorridos por la comunidad observando las cosas que se encuentren, los recorridos se orientan con preguntas que llevan al niño a descubrir su comunidad:

¿QQué cosas observaron? • ¿Cómo eran? • ¿Qué fue lo que más les llamó la atención? • ¿Qué fue lo que no les gustó?

Con estas preguntas se busca que el niño justifique sus respuestas. Siempre que se hace un recorrido el niño representa lo observado, a través de dibujos, cuentos, dramatizados. Cuando el niño ha ganado cierta claridad acerca de su comunidad o entorno pasamos a conocer su historia.

Para conocer la historia de la comunidad se invita al niño y al maestro a investigar y nuevamente, a través de preguntas, despertar inquietudes en los niños. Una vez recogidas la inquietudes de los niños se invita a una persona mayor de la comunidad. Con esta persona se habla con tiempo, se organiza el temario y se le explica que el objetivo de su visita es compartir con los niños sus conocimientos para que ellos conozcan la historia de la comunidad y la cuiden. A través de cuentos o en forma de historieta, se narra la historia de la comunidad, niños y profesoras hacemos preguntas a la persona visitante.

Otra de las actividades es visitar lugares a donde llegaron los primeros habitantes, se buscan las casas más antiguas y se visitan, observan las formas de vestir de la gente en esa época, se muestran algunos vestidos, son cosas que en ocasiones les causa risa a los niños les parece chistoso y generan inquietudes que luego las aclaran con sus padres; otras se trabajan en clase. En este momento que ha empezado a comprender lo que hay a su alrededor se empieza a estudiar aspectos relacionados con la vida de la comunidad. Hacemos dramatizados sobre algunas situaciones que queremos referenciar en el momento como: el trabajo en la comunidad, qué hace el papá, la mamá y los dèmás miembros de la familia, qué hace el tendero, el agricultor entre otros.

En este proyecto de "conocer la historia" las fotografías son valiosas, se indaga con las familias para conocer su archivo fotográfico, las recibimos prestadas y se utilizan de acuerdo al momento o desarrollo del proyecto y se observan con los niños.

La celebración de festividades tradicionales es muy importante en la propuesta, se ha trabajado la fiesta del nacimiento del niño Dios, con los niños se hace el pesebre y con los padres de familia y otras personas mayores de la comunidad se organiza la fiesta del niño Dios, se baila la fuga donde participan niños, jóvenes y adultos; en esta fiesta se integra la comunidad y al ritmo de la música y versos se adora al niño Dios.

Antes de esta ceremonia se trabaja con los niños sobre la gestación, el nacimiento y el crecimiento y la importancia que tiene para todos este encuentro. Preparamos platos típicos de la zona, especialmente los que se preparan con productos nativos. En época de Semana Santa se habla sobre la muerte, se prepara en la Casita, con los Niños, pandebono, se define en qué casa se hace, utilizamos un horno de leña. Los niños se involucran en la armada y horneada del pan que ese día se consume como refrigerio, una parte se lleva a casa para compartir con la familia.

Después de cada actividad se presenta, a través de dibujos o dramatizados, lo que aprendieron; para las pinturas de los niños, además de vinilos y otros elementos químicos utilizamos la tierra de colores, el achiote, hojas y flores de árboles dándole uso a los productos que tenemos a mano. Los niños tocan instrumentos musicales como el tambor, conuno, maracas, platillos, redoblante y bailan al ritmo de la música los bailes típicos de la zona contribuyendo con estas actividades al rescate y fortalecimiento de los valores culturales de la comunidad.

La investigación en sus casas de cuentos o versos para trabajar en clase, se hace relacionado con lo que se está haciendo en ese momento en el proyecto; el reconocimiento del valor del trabajo de cada de los niños nos ha permitido reflexionar en aspectos tan importantes como: la motivación del niño a la investigación, la lectura y la escritura, acercamiento y participación de los padres de familia en el proceso educativo, recuperación y recopilación de cuentos de la tradición oral.

\section{Los exaluminos y jóvenes}

Cuando los niños salen de la casita, continuamos con este trabajo a partir de las vacaciones recreativas, actividades que desarrollamos con niños y jóvenes en la mayoría exalumnos de la Casita; con ellos trabajamos además de otras actividades la historia de la comunidad, donde a través de una ficha o guía son ellos quienes investigan aspectos como:

- ¿Cuándo se construyó el puente?

- ¿Qué productos se cultivaban en la finca?

- ¿Cuáles se cultivan ahora?

- ¿Qué y cómo se enseñaba? 
- Primeras familias que llegaron a la comunidad, ¿de dónde venían?

- ¿El por qué del nombre de la comunidad?, entre otras.

Todo esto se recrea a través de diversas actividades. Contamos con jóvenes con deseo de hacer algo por su comunidad.

\section{Con los padres}

Se realizan talleres de capacitación donde adquieren algunas herramientas para compartir sus conocimientos con los niños. Hemos desarrollado charlas sobre las etapas del desarrollo del niño donde se analiza la capacidad de los niños para entender las cosas; esto se hace con el propósito de garantizar que las personas mayores no se impacienten y logren ganarse la atención de los niños.

Se ha hecho una recopilación de juegos y rondas, coplas, cuentos a través de conversatorios donde se invita un gran número de personas mayores de la comunidad. Hay jornadas para recordar los juegos que se realizaban cuando ellos eran pequeños, se distribuye el personal en equipos pequeños; cada equipo se encarga de preparar uno o dos juegos y luego lo realiza con todo el grupo. Hay una persona que se encarga de hacer la relatoría o sistematización de los juegos, los cuales son empleados en el trabajo con los niños.

En el análisis que se hace con las personas mayores plantean que este tipo de cosas se han ido perdiendo debido a que, cuando apareció la televisión, los niños no dedican tiempo para jugar y, por otro lado, en las escuelas los profesores ya no juegan con los niños y a estos sólo les queda repetir lo que ven en la televisión.

Para la recopilación de los cuentos, versos y otro tipo de manifestaciones culturales se hacen encuentros culturales, hay intercambio de canciones, cuentos, bailes, entre otros, estos se hacen a nivel local y regional. Realizaremos encuentros interétnicos.

A partir de los juegos, los bailes y cuentos se discuten los problemas que afectan a la comunidad como son la calidad de la educación, el agua, las falencias a nivel de producción y muchas cosas más.

El equipo de trabajo de Casita de niños puede decir con certeza, que esta propuesta pedagógica ha contribuido altamente con el proceso organizativo de las comunidades donde se encuentra inmersa. Ha sensibilizado a diferentes comunidades y entidades acerca de la necesidad de implementar procesos etnoeducativos.

\section{Diâlogo del miento}

Crece el número de maestros y maestras de este país, que hacen grandes contribuciones al campo educativo de ese mosaico de la cultura colombiana que más genéricamente llamamos la afro-colombiana. Esta experiencia se ubica en este campo y a nivel formal en el grado preescolar.

Sor Inés, creando "Casitas de Niños" en el Cauca, Colombia, sabe lo que hace: defiende la infancia, la semilla de la cultura afro-americana. Con eso queda bendecida su obra. No importa si la identidad se refunda o se disperse por el paisaje colombiano, como ella trágicamente nos lo cuenta.

En su narración se siente la fuerza de los programas autosugestionados, los que están atados a la fuerza creadora de las comunidades organizadas, sean blancas, negras, indias, mestizas, mulatas, zambos o todo junto, todo diverso como es la obra de la creación, pero trabajando por la continuidad de lo que nos pertenece; a los sentimientos hechos acción, desprendidos de la calificación, el éxito y la rentabilidad económica.

Son procesos que en medio de los insensibles sistemas de poder, léase "Pese a que en Colombia se ha creado el ICBF... los niños no se han beneficiado de este servicio", se convierten en asociaciones comunitarias autónomas.

La voluntad y el empeño que ponen en esta manera de educar a estos niños, los salva de caer en los mundos artificiales, funcionales, racionalistas, mercantilistas y los conserva en la "creatividad, la investigación, la criticidad, la valoración de ellos mismos y de los otros, de la naturaleza de sus costumbres y la proyección de sus aspiraciones al entorno social".

La ayuda llegará con sus aparatos de poder, de burocracia y de ganancia, pero para entonces sus maneras de hacer la democracia, de convivir y de administrar en las que están inmersos se habrán fortalecido y ninguna generosidad condicionada podrá chantagearlos.

A los artefactos industriales y técnicos que están llegando a sus comunidades hay que darles su uso adecuado para que no maten la palabra, sino la amplifiquen para que les ayuden a seguir contando las historias de los viejos, para que sigan construyendo su obra y su historia. Es posible que por esta vía no caigan las comunidades afroamericanas en estos conglomerados humanos que son las ciudades en donde las educaciones y las tecnologías que invaden las instituciones están más para distraer a las masas inactivas y desempleadas, que para revelarse contra esta terrible manera de antiecológica de domesticar y destruir la naturaleza humana.

Héctor F. Espinosa Dchoa Miembro equipo RED-CEE 